\title{
Improving the efficiency of organizing technical service of equipment for processing oilseeds
}

\author{
Valentin Kurochkin ${ }^{1 *}$, Natalia Shcherbak ${ }^{2}$, and Sergey Nazarenko ${ }^{2}$ \\ ${ }^{1}$ South Federal University, 105/42, Bolshaya Sadovaya Str., 344006, Rostov-on-Don, Russia \\ ${ }^{2}$ Moscow State University of Technology and Management named after K.G. Razumovsky (First \\ Cossack University), 73, Zemlyanoy Val Str., 109004, Moscow, Russia
}

\begin{abstract}
In the article presented to your attention, in order to reveal the effectiveness of technical service of equipment for processing oilseeds, the modes of its functioning have been investigated. A multifactor experiment was carried out to determine the minimum costs for organizing the technical service of oil-extracting equipment. The optimal values of the response function Wopt are found, that is, the minimum costs for organizing the technical service of oil-extracting equipment. The response surface has a clear optimum for the following values of the factors: $\{1.32 ; 3 ; 1,022\}$, the regression equation is obtained. Optimization of the technical service of equipment for processing oilseeds according to this equation makes it possible to increase the coefficient of technical utilization from the existing 0.86 to 0.93 , which increases shift productivity and annual production of vegetable oil by $7.0 \%$ with a slight increase in total labor costs by $6.69 \%$ due to the increase in the number of repair and technical workers and the strengthening of the service of the chief engineer of the enterprise.
\end{abstract}

\section{Introduction}

There are oil-extracting enterprises in the Rostov region, the production capacities of which significantly cover the needs of its population, therefore, most of the vegetable oil is exported. The Rostov Region provides $60 \%$ of the export of Russian vegetable oils. Since 2006, the reconstruction of the oil and fat industry has been carried out, it was based on the introduction of innovative technologies, on the construction of new and re-equipment of existing oilextracting enterprises. Reconstruction and new technologies have created conditions for increasing the efficiency of the use of OPSMK and increasing the competitiveness of manufactured products. In 2020, the production of vegetable oils in the Southern Federal District amounted to more than 1.6 million tons, which is $10 \%$ more compared to the same period last year.

According to forecasts, after the completion of modernization and reconstruction, the largest enterprises of the Rostov region will be able to process 12.9 million tons of oilseeds per year. However, the reality is that oilseed processing equipment (OPSMK), even the most advanced, requires maintenance, including troubleshooting. To increase the efficiency of the functioning of the technological equipment of enterprises for the production of vegetable oils for technical reasons can be achieved by improving the organization of the engineering service [1]. 
Known research on digital technologies of equipment service in various sectors of the economy. Here is a brief overview of research in the industries: information, telecommunications, mechanical engineering, energy, automotive.There is domestic and foreign experience. For example, digital shaping of future maintenance operations using augmented reality is being developed. Industrial sectors like mechanical engineering currently define themselves primarily through their product business. However, a change can currently be observed. Instead of continuing to engineer products for maximum reliability, solution systems are developed that leverage their performance from services such as maintenance. For these, information supply is an essential factor, since the underlying products are becoming more complex. Additionally, these products are integrating information and communication technology, which can supply technicians, e.g. with actual condition data. To be able to use this information, technicians need service support systems (SSS) that yet exist on mobile and simple wearable devices. This article reports from the development of an SSS-based on augmented reality glasses. The developed system was used to support a LEGO assembly task and evaluated with the Task-Technology Fit model. The result shows that AR glasses can be used for the information supply of technicians but still need further development to allow for adequate service support [1],[2], [3], [4].

In the energy industry, leading companies are striving to harness digital innovation and all the benefits they offer for forecasting Yet some of the largest companies still rely on sporadic, manual inspections to ensure the smooth operation of their machinery, equipment, instrumentation and systems. One international oil and gas company realized even the most skilled plant technicians could miss certain warning signals. If equipment like heat exchangers, pumps or critical valves are checked only periodically, manufacturers can risk equipment failure, outages or worse - health and safety incidents. Thanks to advancements in the quality and affordability of sensors as well as wireless technologies and cloud-based applications to gather and analyze data being streamed from devices in the field, companies like this one can gain better insights from equipment and take proactive measures to prevent failures and plant shutdowns. The company worked with third-party technology vendors to implement a predictive reliability and maintenance program that will save millions of dollars a year in operational costs by instrumenting and monitoring heat exchangers in one of the company's refineries. The program is designed to digitally transform the company's heat exchanger maintenance activities and free refinery personnel from laborious manual monitoring, enabling them to focus on other functions and operational needs. A typical refinery will have 200-400 heat exchangers, the majority of which are manually monitored, with months passing between inspections. If undetected, heat exchanger fouling can cause degraded performance, reduced energy efficiency, process slowdowns and unscheduled shutdowns. Installation of more sensors to drive plant monitoring applications is an option, but the cost and disruption of installing new, conventional wired temperature sensors to an existing facility is prohibitive. One of the vendors developed and installed unique costeffective sensors to provide accurate measurements from the refinery's heat exchangers without thermowell process penetration. These sensors allow for remote monitoring of heat exchanger data in real time. As part of the ongoing program, the data is transmitted through a secure, wireless architecture and transferred to the cloud using cloud-computing technologies. Using advanced analytics, the data is then interpreted to provide plant personnel with actionable data to optimize operational performance. Results, Observations, Conclusion: There have been significant savings in sensor installation (a fraction of the cost of conventional sensors) and commissioning time (one week versus the typical six weeks). The plant has also seen savings in staff time. The company can detect small variations well before any fouling issues start. The program is proving that, by understanding the health of the heat exchangers, the company can help prevent unplanned outages and reduce the number of scheduled repairs. Facilities can reduce energy and capacity loss due to fouling by up to 
10 percent. For a 250,000-barrel-a-day refinery, that could translate to a savings of as much as $\$ 3.5$ million or more annually. Wireless sensors and secure, cloud-based condition monitoring can be expanded to other equipment, such as pumps and cooling towers throughout the plant. Ultimately, these predictive maintenance programs will improve and transform operations, and the data analytics and insights will accelerate business decisions. Cloud-based hosting of these monitoring systems allow monitoring by any personnel, anywhere, including the option of having a third-party vendor provide the service [5].

This project endeavored to design and develop a Web-based Automobile Service Management System for MAS Motors LLC, an accredited Toyota dealership in Libya. The system will help reduce the manual process from the everyday activities of the service division in all branches. The system is dedicated to be used by the following individuals: (1) Service Advisers, (2) Workshop Managers, (3) Storekeepers, (4) Technicians, (5) Customers, and (6) Upper Management. The company's growth made the manual process ineffective and incompetent in handling the evolving business activities. The project aimed to provide a centralized system that will operate in all of the branches and accommodate the daily business needs. The software produced from the project was tested using Alpha and Beta software testing. The researcher also conducted an interview concerning the business process, current business difficulties, and features of the proposed system. Hewlett-Packard FURPS (Functionality, Usability, Reliability, Performance, and Supportability) model was used to assess the software quality, and questions were answered by a group of respondents. The system was found to be functional, meeting the requirements of the client. [6]

French scientists have tested the results of the analysis of organizational forms of maintenance. [7]

The past years have seen the telecommunications network and services increase in their complexity due to changes in traffic patterns, usage of the network and applications. This is in part driven by the growing customer base, services, broadband usage and complicated by the presence of multiple types of equipment vendors, technology and software systems. One consequence of these is the increase in the breakdown of telecommunication equipment serving end-users. The equipment failure, in turn, necessitates field technicians to visit onsite premise frequently to troubleshoot and resolve customer trouble tickets (CTTs). In this paper, Markov Process (MP) is used to represent the CTTs as a sequence of events and analyze the tendency of one type CTT to be followed by another type of CTT. By observing existing sequences of CTT types, a MP model can approximate the likelihood of the next CTT occurring followed by current CTT type. With this knowledge, technicians can act proactively to preempt network problems. The analysis uses one year of CTT records raised by the subscribers of a leading broadband service. The analysis observes that in most cases current CTTs are influenced by previous CTT types and mean time between failures (MTBF) is different for the same CTT types [1].

The findings show that the inefficiency resulted from lack of training, inadequate maintenance schedules, and inappropriate location where maintenance is conducted. For remediation and mitigation purposes, it is recommended that proper techniques and preventive practices and schedules be implemented; good frequent training and performance assessment of the engineers and technicians be regularly conducted. In addition, a proper review of the asset service design, and the location of maintenance site be overhauled in the entire value chain [8].

Error analysis for approximate structural life-cycle reliability and risk using machine learning methods [9].

Implemented structures for proactive maintenance using failure prediction and lossless protection with an offline network diagnostics system. Advanced Predictive and Intelligent Analysis Methods for Machine Life Extension [10]. Success of manufacturing companies largely depends on reliability of their products [11]. 
However, research into the technical service of equipment for processing oilseeds is not enough to improve production efficiency. Questions of research of the organization of maintenance remain topical. The goal was set: to establish the efficiency of technical service of equipment for processing oilseeds.

Based on the performed analytical review of works in this direction, the following was established.

\section{Methods and materials}

The experiment planning method was used. The scientific and methodological base of the research was made up of fundamental work that was carried out by researchers of the scientists of the Azov-Black Sea Engineering Institute, Donskoy GAU, Agrarian Scientific Center "Donskoy" VIM, GOSNITI, VNIITiN and other scientific institutions.

\section{Results and discussion}

The research carried out in the above scientific institutions made it possible to create an effective system for the maintenance and repair of MTP, to solve methodological problems of managing its reliability, but the OMSM service has not been sufficiently studied. Scientific development of the tasks of the engineering service at oil-extracting enterprises, including the organization of equipment, lags behind the requirements of the time, and the existing knowledge about the reliability of equipment for processing oilseeds is not enough to build a system for managing its reliability [12], [13],[14], [15].

Research on equipment failures of varying complexity has shown that "wear of parts and assemblies of machines and equipment occurs during operation and is more dependent on the operating mode, as well as factors influencing the operating modes. This will prevent equipment failure and increase the technical availability, as a result, reduce the cost of repairs and equipment downtime", which is consistent with research data on the reliability of equipment used in agriculture [12] [13] [14]. Consequently, the engineering staff of the enterprise needs to direct certain efforts to create a modern system for managing the reliability of equipment for oil production. Earlier [15] we improved the system of organizing technical service of an enterprise for processing oilseeds, developed algorithms for computer control of the reliability of the technological system for using the OPSMK.

We considered the effectiveness of improving the organization of technical service of equipment for processing oilseeds. The objective function can be defined as the sum of losses from equipment downtime due to failures and stations from their downtime according to the formula 2.52, or as the sum of costs and damage from downtime according to the formula 2.53. taking into account the period of $\mathrm{T}$.

The idle posts in the service system are associated with damage from downtime, and with the loaded ones - the costs of operation. The more the post is loaded, the higher the cost of its operation, and the longer the post is idle, the more losses from downtime.

Optimization consists in finding the point at which the sum of losses and operating costs is minimal. The following significant factors affect the efficiency of the technical service subsystem: $(\mathrm{Mo}+\mathrm{Mo}+\mathrm{M})$ - the average number of requests for service and in the queue; $\mathrm{k}$ is the number of posts; LF - the cost of a standard hour when the team is working at the maintenance post.

A multifactor experiment was carried out to determine the minimum costs for organizing the technical service of oil-extracting equipment.

We applied a planning matrix for a three-factor experiment. Each factor was varied at three levels: -1.0 and +1 . 
The levels of the factors and the intervals of variation are presented in Table 1.

Table 1. Values of the levels of factors and intervals of variation.

\begin{tabular}{|c|c|c|c|c|l|}
\hline \multirow{2}{*}{ Designation } & \multicolumn{3}{|c|}{ Levels } & \multirow{2}{*}{ Intervals } & Name of factors \\
\cline { 2 - 4 } Mo + Can & 1.09 & 1.32 & 1.61 & 0.26 & $\begin{array}{l}\text { Average number of requests for } \\
\text { service and queues }\end{array}$ \\
\hline$k$ & 1 & 3 & 5 & 2 & Number of posts \\
\hline$H_{t}$ & 1.43 & 1.022 & 1.567 & 0.0685 & $\begin{array}{c}\text { The cost of a standard hour when } \\
\text { the team works at the maintenance } \\
\text { post }\end{array}$ \\
\hline
\end{tabular}

It was found that this function has an optimum, which allows using the obtained model to control the reliability of oil-extracting equipment. Spatially, the response function is shown in Figure 1.

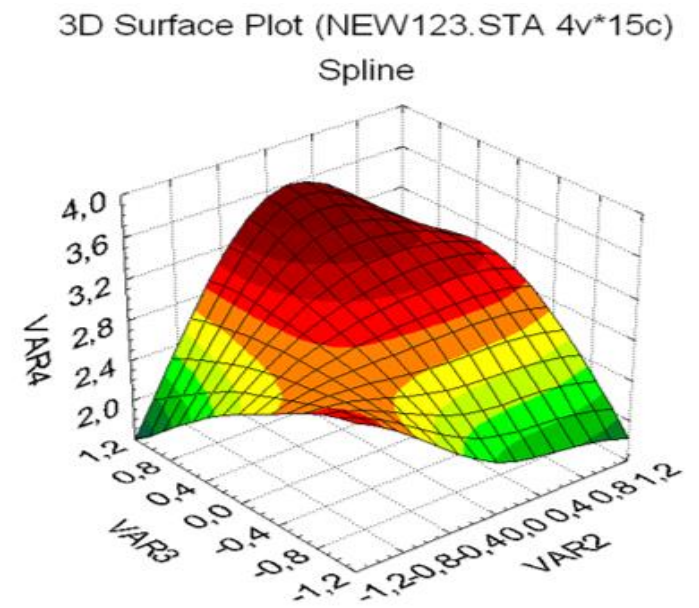

3D Surface Plot (NEW123.STA 4v*15c)

Spline

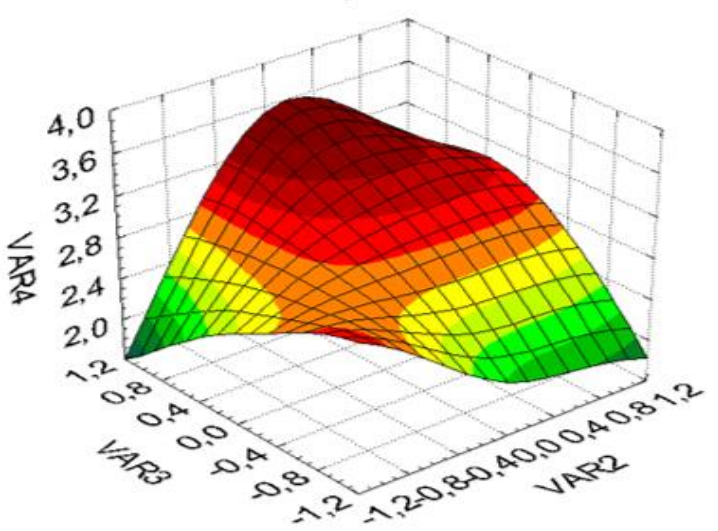




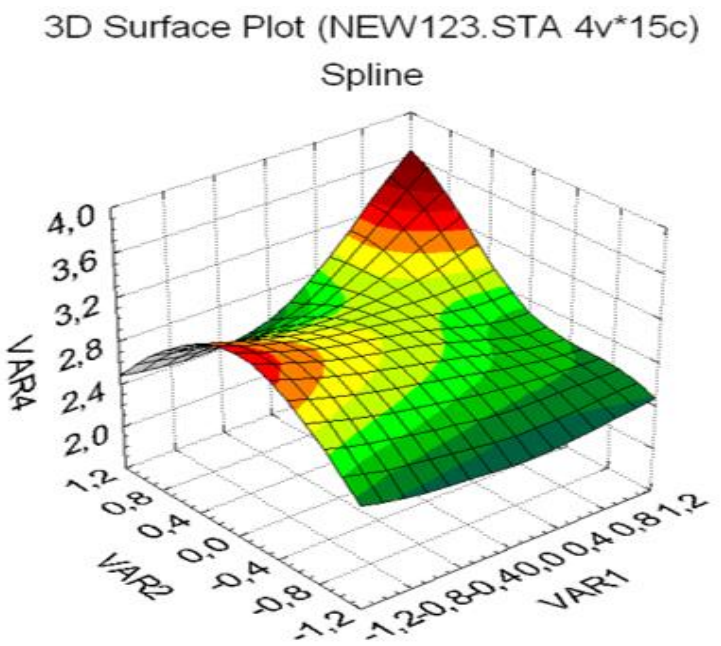

Fig. 1. Response function in space: $\operatorname{VAR} 1=(M o+M o z h) ; \operatorname{VAR} 2=k ; \operatorname{VAR} 3=$ Low.

The significance of the regression coefficients was checked by the Student criterion, its value is 4.8 , which is less than the tabular value, the computer program confirms the significance of the results, at a 5\% significance level.

Three series of experiments were carried out, each series contained 15 experiments, on the basis of which the response functions of the optimization parameter were obtained in the form of a polynomial of the second degree

$$
\begin{aligned}
& W=2,99+0,682 M+0,928 k+0,63 H t+0,15 M k+0,49 M H t+0,2 t H t+0,119 M^{2}- \\
& 0,133 H t M^{2} .
\end{aligned}
$$

Optimal values of the response function Wopt, that is, the minimum costs of organizing technical service for oil-extracting equipment.

As a result of the 3-factor experiment, the response surface has a clear optimum for the following factors: $\{1.32 ; 3 ; 1,022\}$, the regression equation is obtained. Optimization according to the developed equation (2) increases the coefficient of technical use of Kti from the existing 0.86 to 0.93 , which increases the shift productivity and the annual production of vegetable oil by $7.0 \%$ with a slight increase in total labor costs by $6.69 \%$ due to an increase the number of repair and technical workers and the strengthening of the service of the chief engineer of the enterprise. As a result of the introduction of a modernized maintenance organization at an oil-extracting enterprise, unproductive downtime of equipment and production personnel is reduced, the economic effect from the implementation of the reliability management system will be about 54 million rubles, with a payback period of less than a year. The results obtained are consistent with the results of foreign studies [6-7].

\section{Conclusion}

The effectiveness of the developed organization of technical service of equipment for processing oilseeds, which was obtained by increasing the coefficient of technical utilization of KTI by 0.07 or $11.0 \%$, has been proven, the effect fully pays for the costs of its implementation. 


\section{References}

1. M. K. Hossain, M.S. Shahrir, M. I. Yusof, et al., IEEE Conference on Big Data and Analytics: ICBDA 2017. Malaysia. 16 November (2017)

2. A. Sapena-Banoa, F. Chinestab, R. Puche-Panaderoa, et al., International Journal of Electrical Power \& Energy Systems, 125, February (2021)

3. K. Nordberg, A. Mariussen, S, Virkkala, Journal of Rural Studies, 79, 157-168 (2020)

4. F. Kammler, J. Brinker, J. Vogel, T. Hmaid, O. Thomas, How do we support technical tasks in the age of augmented reality. Some evidence from prototyping in mechanical engineering, 40th International Conference on Information Systems, ICIS 2019 (2020)

5. P. Zornio, M. Boudreaux, Case study: How digital transformation paved the way for one refinery's predictive maintenance strategy. Proceedings of the Annual Offshore Technology Conference (May 2019)

6. A. Shahlol, A. Alix, A. Lagman, Web-based automobile service management system for MAS motors LLC. IEEE. 10th International Conference on Humanoid, Nanotechnology, Information Technology, Communication and Control, Environment and Management, HNICEM, 8666420 (2019)

7. C. Grusenmeyer, Maintenance: Organizational modes, activities and health and safety. Use of a French national survey and in-situ analyses. Accident. Analysis and Prevention, 73, 187-199 (2014)

8. T. Seletlo, A. Telukdarie, O. Nwauka, The reliability of $43 D$ diesel locomotives on the phalaborwa to Richards Bay corridor 2018. Proceedings of the International Conference on Industrial Engineering and Operations Management (JUL), 536-545 (2018)

9. D. Y. Yang, D. M. Frangopol, X. Han, Structural Safety, 89, 102033 (2021)

10. W. Rinnanont, A. Bamrungwong, G. Teerawongsakul, Advanced Predictive and Intelligent Analysis Methods for Machine Life Extension 2019. Petroleum and Chemical Industry Conference Europe Conference Proceedings, PCIC EUROPE. May, 9011559 (2019)

11. R.Sipos, D. Fradkin, F. Moerchen, Z. Wang, Log-based predictive maintenance. Proceedings of the ACM. SIGKDD International Conference on Knowledge Discovery and Data Mining, 1867-1876 (2014)

12. S. L. Nikitchenko, V.N. Kurochkin, A. A. Seryogin, N. V. Valuev, V.P. Zabrodin, V.S. Gazalov, Journal of fundamental and applied sciences, 9, 742-751 (2018)

13. V. N. Kurochkin, A.F. Reva, E.V. Voronov, E.R. Mikhailova, A.V. Stepanov, N.N. Pushlarenko, Modernization of the organization of maintenance of the machine and tractor fleet of agricultural organizations, The 35th IBIMA conference will be held in Seville. Spain 1-2. April (2020)

14. Feng Huijuan, Liu Xiangkai, Yang Wancheng. An Aggregation Method for Mission Reliability of Equipment Support Object System, Series: Advances in Intelligent Systems Research. Proceedings Article: International Conference on Electronic \& Mechanical Engineering and Information Technology (EMEIT-2012), 2291, 22295 (2012)

15. V. N. Kurochkin, S. A. Nasarenko, N. A. Schebak, Digital technologies for managing the reliability of machines during maintenance. IOP Conference Series: Materials Science and Engineering, 1001 (2020) 